\section{La odontología forense y su aplicabilidad en el procesamiento de escenas del crimen y demás eventos catastróficos}

\author{
Forensic Odontology and its applicability in processing crime scenes \\ and other catastrophic events
}

\begin{abstract}
Resumen
En los últimos años la odontología forense alcanza a nivel mundial fundamental importancia, consiguiendo, mediante determinados procedimientos, estimar hora y fecha de muerte de una persona, facilitando la resolución de múltiples y complicados casos de muerte. Los procedimientos empleados también permiten el levantamiento de huellas aplicando técnicas para queiloscopía, mordidas, registro de rugas palatinas, brindando de esta forma un gran aporte en la investigación criminal en su primera fase indagatoria, dentro de la cual el procesamiento de la escena busca colectar indicios y evidencias vinculantes al hecho, que posteriormente a través de una cadena de custodia se trasladarán al laboratorio donde los indicios y evidencias serán estudiados, pasando a ser medios de prueba pericial para poder identificar el hecho y la autoría de un acto presuntamente criminal. Se presenta así una recopilación de literatura concerniente al tema que busca informar al odontólogo de practica general sobre terminología, procedimientos y demás relacionados a las ciencias forenses, con el propósito de informar y actualizar sus conocimientos al respecto.

Palabras clave: Crimen, Diagnóstico, Muerte, Dentistas, Rigor mortis.
\end{abstract}

\section{Abstract}

In recent years, forensic dentistry reaches critical importance worldwide, getting through certain procedures to estimate, time and date of death of a person, facilitating the resolution of multiple and complicated cases of death. The procedures employed also allow the lifting of fingerprints by applying techniques; Queiloscopía, Biting, Registration Rugas Palatine, providing thus a great contribution in the Criminal Investigation in its first phase Inquest, within which the processing of the scene seeks to collect evidence and binding evidence the fact that subsequently through a chain of custody is transferred to the laboratory where the evidence and evidence will be studied, becoming media expert evidence to identify the fact and authorship of an allegedly criminal act, thus presents a collection of literature concerning the subject that seeks to inform the general practice dentist on terminology, procedures and other related forensic sciences in order to inform and update their knowledge about it.

Keywords: Forensic dentistry, Crime scene.

\section{Artículo De Revisión}

Roberto. D. Chango-Iza', Osmani. F. Guevara-Cabrera ${ }^{3}$, Ana del Carmen Armas-Vega ${ }^{4}$
1. Egresado de la Especialidad en Estomatología Forense de la Facultad de Odontología de la Universidad Nacional Mayor San Marcos Lima-Perú.

2. Docente de la Facultad de Odontología de la Universidad Internacional del Ecuador. Perito Calificado y Acreditado Consejo Nacional de la Judicatura del Ecuador.

3. Universidad Central del Ecuador.

4. Docente de la Sección Operatoria Dental de la Universidad Tecnológica Equinoccial.

Correspondencia:

Osmani. F. Guevara-Cabrera:

fabriche20@hotmail.com Macas, Ecuador

Roberto. D. Chango-Iza:

odontosonrobert@hotmail.com Quito, Machachi, Ecuador

Ana del Carmen Armas-Vega:

ana_del_ec@yahoo.es Quito, Tumbaco Ecuador

Fecha de Recepción: 10/11/2015

Fecha de Aceptación: 29/04/16

\section{Introducción}

El aporte que la odontología forense ha brindado al trabajo que se realiza en la escena del crimen viene siendo fundamental a lo largo de los últimos años. La escena del crimen es considerada como el lugar donde se presume se ha cometido un delito; por ende, el lugar objeto de una investigación policial, de importancia evidente por la gran cantidad de indicios o evidencias que se puede recoger en ella, las que serán determinantes en el desarrollo de la investigación criminal. ${ }^{1}$

La cavidad bucal es considerada, por sus numerosas estructuras, duras y blan- das, como la "caja negra"' del cuerpo humano. ${ }^{1}$ Las estructuras duras como dientes y huesos maxilares aportan gran información para el proceso de identificación, siendo no menos importantes los tejidos blandos, como el paladar y los labios, pues contribuyen con datos interesantes al dejar marcas, surcos, estrías y rugosidades, que cumplen con las propiedades de los métodos de identificación al permitir individualidad, inmutabilidad y perennidad. $^{2}$

Se plantea la ejecución de una investigación de carácter analítico, donde se eligieron diez artículos de entre veinticinco seleccionados a partir de criterios de inclusión requeridos para este análisis bibliográfico, en el cual se incluyen imágenes donde participa el odontólogo forense en la escena del crimen. Es muy importante el análisis de la data de muerte hasta la aplicación de métodos para identificación humana, ya sea de la víctima o del autor del hecho, y de esta forma dar a conocer que el actuar del odontólogo forense no es únicamente en el laboratorio puesto que en el lugar de los hechos se puede levantar indicios y evidencias que son responsabilidad de este profesional. Con este fin realizamos este artículo de revisión bibliográfica ,donde revisamos imágenes de la escena 
del crimen, analizamos mediante queiloscopía la presencia de indicios acerca de la muerte del individuo, aprendimos cómo reconocer un cadáver a través de las rugas palatinas o si estas corresponden al que ejecutó dicho acto.

\section{La odontología forense}

Definida como una especialidad que, apartándose de la terapéutica, forma un lazo de unión entre la odontología y el derecho, en lo que respecta al cumplimiento de las leyes, la aplicación de sus conocimientos odontológicos al servicio de la justicia, ${ }^{3}$ al recoger indicios y evidencias en la escena del crimen, aplicando métodos para identificación humana en la víctima o en los presuntos autores del hecho. ${ }^{4}$ Los indicios y evidencias al ser trasladados y estudiados en laboratorios especializados permiten la emisión del informe o peritaje.

Las evidencias están respaldadas generalmente con fotografías, describen y verifican hechos, tanto en el cuerpo de la víctima o de los implicados.

Un fenómeno común en las investigaciones para la data de la muerte constituye la rigidez cadavérica. De manera general tras la muerte de un individuo existe una fase de relajación muscular de horas o minutos, hasta la instauración de un lento proceso de contracción muscular, conocido como rigidez cadavérica, donde los músculos se contraen, endurecen y retraen, provocando un bloqueo de las articulaciones, que deja el cuerpo rígido, formando un bloque. ${ }^{5}$ En este proceso la articulación temporo - mandibular (ATM) quedará fija por contracción muscular, por la relación del cóndilo mandibular con los haces superior e inferior, del músculo pterigoideo externo y con varios ligamentos, que aúnan esfuerzos para hacer más evidente el rigor mortis, externamente el ligamento lateral y en el interior de la articulación su menisco, responsable de la movilidad de la articulación, junto con la cápsula generalmente laxa. ${ }^{5}$

El Criminal Profiling, considerado como técnica creada por el FBI, consiste en describir el comportamiento probable del autor desconocido de uno o varios asesinatos. ${ }^{6}$ Se le divide en fases con el objetivo de tener una metodología estándar que ayudará a un procesamiento correcto de las escenas de crimen. Por otro lado, la aplicación de reactivos basados en la fluorescencia para huellas dactilares brinda buenos resultados en el revelado de huellas labiales sobre superficies porosas oscuras o multicolores ${ }^{7}$; sin embargo, la calidad dependerá del tipo de lápiz labial y de la antigüedad de la misma. La aplicación de la luz Bluemaxx TM mejora el resultado, puesto que con ella la manipulación de la huella es menor.

Otro fenómeno estomatognático asociado con la rigidez cadavérica es el bruxismo, asociado a la actividad electromiográfica de maseteros y temporales, evidenciándose en personas con bruxismo durante el sueño la doble actividad muscular masticatoria rítmica y de mayor duración, provocando un cierto cansancio muscular, que frente a la muerte se asocia a la instalación precoz de los procesos de rigidez. ${ }^{5}$

Pese a todas estas afirmaciones, muchas investigaciones precisan ser ejecutadas sobre este tema y es de destacar cómo actualmente existe una tendencia a emplear el conocimiento entomológico en la determinación de la escena del crimen. Estos estudios han merecido destaque y poco a poco van siendo aceptados en la práctica de la medicina forense, y son conocidos como entomología forense o médico legal ${ }^{8}$; de la misma manera, el láser scaner 3D Trimble Mensi, cuyo uso ha sido ampliamente reportado en terremotos, accidentes de todo tipo y casos de muertes en general ,con grandes resultados. ${ }^{9}$

\section{La queiloscopía}

Término derivado del griego "cheilos", labio, y "skopein", examinar. Se refiere al estudio, registro, clasificación y cotejo de las configuraciones de los labios, ${ }^{10}$ basado fundamentalmente en la caprichosa disposición que adquieren en su recorrido por los labios superior e inferior, que toma fuerza en la existencia de una serie de pliegues, surcos, fisuras. Estos al ser examinados debidamente ofrecen datos de interés para la identificación de una persona, ya que las huellas dejadas por los labios no se repiten de una persona a otra, más aún cuando estas tienen patologías congénitas, ya que dejan características aún más individualizantes, ayudando de una forma eficaz, rápida, confiable, económica a la identificación positiva de un individuo sospechoso de un hecho delictivo cuando se procede en forma inmediata, brindando, por consiguiente, un valioso aporte a la criminalística en el estudio del lugar de los hechos, ${ }^{11}$ que puede ser el indicio que señale el rumbo que ha de seguir la investigación.

La queiloscopia es considerada como análoga al análisis de las huellas digitales. ${ }^{12} \mathrm{Al}$ igual que el resto del organis- mo, los labios a veces sufren distintas alteraciones de gran interés: la presencia de una cicatriz producida de una forma congénita constituye una señal particular que va a disminuir el riesgo de error en la identificación. ${ }^{13}$ En diversos países como Venezuela la queiloscopía se ha constituido en la prueba penal para demostrar la identificación positiva de un sospechoso o responsable de un hecho punible, ${ }^{14}$ favoreciendo la capacidad de respuesta sobre delitos violentos, basándose en que la identificación humana debe ser indubitable, rápida, accesible económicamente, por lo que los métodos y técnicas utilizados deben conllevar esto.

Por otro lado, ciertas patologías congénitas del tipo labio fisurado, labio doble o la foseta congénita permitirían características especiales de huellas labiales dejadas en el lugar de los hechos para la identificación, que tomadas en cuenta como una de las muchas características que podemos encontrar en los labios, hacen pensar que la queiloscopía, en un futuro, sea tomada en cuenta como un método de identificación en muchos de nuestros países.

La heredabilidad en queiloscopía como herramienta para la identificación y la determinación de paternidad son hipótesis que aún están siendo investigadas, ${ }^{15}$ pudiendo determinarse que las huellas labiales son invariables, permanentes y clasificables, aunque no sean únicas puesto que conservan similitud entre gemelos monocigóticos. De la misma manera, los surcos labiales y las rugas palatinas han sido consideradas como patrones morfológicos que permiten identificar a una persona. Para esto se necesita investigación y de un sistemático diseño experimental, una base de datos antemortem y el análisis de los códigos procesales para la inclusión de estos rastros como evidencia jurídica ${ }^{16,17}$ con resultados de confiabilidad probados en diferentes estudios. ${ }^{18,19}$

De esta manera, las características anatómicas especiales de los labios afectados con diferentes patologías dejan huellas diferentes, individualizantes e identificables. Se consideran las estrías presentes en los labios, clasificándolas según lo propuesto por Suzuki y Tsuchihashi, ${ }^{2}$ en seis tipos: verticales completas, verticales incompletas, ramificadas o bifurcadas, entrecruzadas, retículas y otras formas. Así, mediante un análisis queiloscópico será básico en los procesos de identificación, útil en labios normales, ${ }^{10}$ más rápido y con me- 
nos riesgo de error ${ }^{20}$ en labios afectados con alguna patología.

\section{La mordedura}

Es considerada dentro de la odontología forense como una lesión contusa por la acción de morder, producida por un mecanismo combinado de presión y tracción. El dogma central en el análisis de las mordeduras está basado en dos suposiciones. ${ }^{21}$ En primer lugar, en que la dentadura humana es única (exclusiva de cada individuo); y en segundo lugar, en que existen suficientes características diferenciadoras entre ellas que posibilitan la identificación.

La mordedura desde el punto de vista médico legal se considera como el daño producido al morder sobre la superficie corporal de una víctima, ${ }^{22}$ en agresiones mutuas, violencia por género y un caso de homicidio en grado de tentativa, considerando a la mordedura como importante evidencia médico legal.

Las rugas palatinas son estructuras anatómicas en relieve que se presentan en la porción anterior del paladar, justo por detrás de los dientes anterosuperiores y de la papila incisiva, bilaterales a la línea media, obtenibles no solo con impresión de la mucosa per se, sino de aparatos protésicos y ortopédicos. ${ }^{23} \mathrm{Su}$ clasificación se encuentra basada en su número, forma, tamaño y ubicación. Estas persisten toda la vida, desde su aparición en el tercer mes de gestación, convirtiéndose en elementos únicos en cada persona, incluso entre gemelos. Por su ubicación se encuentren relativamente protegidas por los labios, los dientes, la bolsa adiposa de Bichat en carrillos y los huesos maxilares, lo que hace que sean menos afectadas tras la muerte del individuo por la descomposición e incineración, convirtiéndolas en elementos valiosos y aceptados en la identificación, equiparándolas con las huellas dactilares, ${ }^{23}$ probadas ampliamente en diferentes investigaciones. ${ }^{24}$

La escena del crimen, dentro de la odontología forense, es la fuente de información del perito y su pesquisa; consecuentemente, es el lugar donde se ha producido un hecho, in prima face, delictuoso y, que por ende, amerita una adecuada investigación, ${ }^{1}$ donde el odontólogo forense debe ser parte fundamental por el aporte de su experticia en dientes, ${ }^{23}$ teniendo en cuenta la amplitud de esta profesión y el criterio adecuado para realizar un trabajo ínte- gro en el recojo de indicios y evidencias en el lugar de los hechos.

$\mathrm{Al}$ analizar la literatura podemos reforzar la importancia que la odontología forense tiene en la escena del crimen, existiendo un nuevo horizonte a ser explorado, donde el actuar del profesional preparado en este amplio campo puede desenvolverse. La escena del crimen es la fuente de información del perito y su pesquisa; consecuentemente, es el lugar donde se ha producido un hecho, in prima face, delictuoso, y que por ende, amerita una adecuada investigación, ${ }^{1}$ que convierten al odontólogo forense en un componente clave en el equipo de reconocimiento e identificación cuando así se lo estime necesario.

La huella labial encontrada en la escena del crimen puede ser el indicio que señale el rumbo que ha de seguir la investigación. ${ }^{11}$ La cultura criminalística de todos nosotros, por ende, requiere ser actualizada, llevándonos a aprovechar todos los indicios y evidencias que el contacto con el individuo en calidad de paciente nos puede brindar para, en determinado momento, colaborar en procesos de investigación con el profesional odontólogo forense. Pasando así, de una práctica cotidiana muchas veces limitada a dientes, ${ }^{23}$ a un proceso amplio y hasta el momento poco explorado, participando de forma activa en un trabajo íntegro, recogiendo indicios y evidencias del lugar de los hechos. ${ }^{25}$

Revisamos varias fuentes bibliográficas e imágenes que nos ilustran el actuar del odontólogo forense en la escena del crimen, dentro está la recolección de indicios y evidencias para ser trasladados y estudiados en el laboratorio, pudiendo de esta manera tener como resultado medios de prueba, que serán emitidos en el informe o peritaje.

Considerando como primer paso en la identificación de la escena del crimen las evidencias fotográficas, evaluaciones de rastros de huellas de labios en la víctima, mordeduras en su cuerpo, entre otras, permitirán visualizar a los peritos en el tema las circunstancias en que los hechos acontecieron, tan importantes como la identificación misma de la víctima realizada empleando el análisis de rugas palatinas, labios, dientes y demás, que bien pueden ser considerados como un dato muy confiable y seguro de identificación. Siguiendo todos estos procedimientos, el odontólogo forense está en potestad de actuar e emitir un análisis como fuente de aclaración del acto. $^{10,16}$

\section{Conclusiones}

Cada vez resulta más frecuente tener en una escena donde existen pérdidas humanas un odontólogo forense, no solo por sus conocimientos en cuanto a mordida, que cada vez la acercan por sus materiales y técnicas de procesamiento a resultados más confiables, sino y sobre todo por la incorporación como un aliado estratégico y asesor permanente de estas escenas por su perspectiva por el conocimiento humano que posee. El futuro se muestra amplio y promisorio para la odontología forense, llevándonos a pensar en una futura jerarquización de expertos y de conocimientos e incluso subespecializaciones dentro de esta misma área.

\section{Referencias bibliográficas}

1. Pasquerault T, Vincent B, Dourel L, Chauvet B, Gaudry E. Los muestreos entomologicos: de la escena del crimen a la peritacion. Ciencia Forense 2006; 8: 39-55.

2. Ciocca L. Odontología Médico-Legal (2da ed). Santiago, Chile: Ediciones Jurídicas de Santiago. 2009.

3. Caballero H. Odontología Legal y Forense, Elementos de Criminalística. Lima, Perú: Centro de Producción Editorial e Imprenta UNMSM.2010.

4. Stamm ADB. Estudio descriptivo del nivel de conocimiento en Argentina sobre la Queiloscopía como sistema de identificación. Gaceta internacional de ciencias forenses. 2012; (5):27-32.

5. Molano Osorio M, Mejía MDP, Ardila Medina CM. Participación del odontólogo en la determinación del diagnóstico de la causa de muerte y del intervalo postmortem. Medicina Legal de Costa Rica. 2009; 26(1):23-31.

6. Serrano JJ. La escena del crimen en el "crimial profiling"(I). Quadernos de criminología: revista de criminología y ciencias forenses. 2009; (6):37-44.

7. Castelló Ponce A, Álvarez Segui M, Negre Muñoz MC, Verdú Pascual FA. Revelado de huellas labiales invisibles con reactivos fluo- 
rescentes. Cuadernos de Medicina Forense. 2003; (34):43-47.

8. Mavárez-Cardozo MG, Espina de Fereira AI, Barrios-Ferrer FA, Fereira-Paz JL. La entomología forense y el neotrópico. Cuadernos de Medicina Forense. 2005; (39):23-33.

9. Soubra OP, Lorenzo A. Aplicaciones de láser escáner 3D Trimble-MENSI en estudios de accidentes y de criminología (forensics). en VIII Congreso nacional de Topografía y Cartografía. TOPCART. (2004, October).

10. Stamm ADB. Estudio descriptivo del nivel de conocimiento en Argentina sobre la Queiloscopía como sistema de identificación. Gaceta internacional de ciencias forenses. 2012; (5):27-32.

11. Cordero AM, Fonseca RH. Identificación en odontología a través de los tejidos blandos. Ciencia forense: Revista aragonesa de medicina legal. 2005; (7):111-124.

12. Hernández JCM, Pabón YNO, Paredes JFM. Identificación de sexo mediante queiloscopia en Santander, Colombia: una herramienta para la medicina forense. Estudio inicial. Revista Española de Medicina Legal. 2015; 41(3):111-116.

13. Negre Muñoz MDC. Nuevas aportaciones al procesado de huellas labiales. Los lisocromos en queiloscopia. 2004.
14. Chicón JM. Propuesta de una simbología odontológica y su utilidad en el análisis de la diversidad dental para la identificación forense. Editorial Universidad de Granada. 2014.

15. Barragán MCT. Estudio de la heredabilidad en la Queiloscopia. Revista de la Escuela de Medicina Legal. 2011; (17):32-44.

16. Fonseca GM, Cantín M, Lucena J. Odontología Forense III: rugas palatinas y huellas labiales en identificación forense. International Journal of odontostomatology. 2014; 8(1):29-40.

17. Herrera LM, Fernandes, CMDS, Serra MDC. Identificação humana por meio da Queiloscopia convencional e digital: um estudo da literatura. RGO. Revista Gaúcha de Odontologia (Online). 2013; 61(1):113-120.

18. Bernardoni M, Sauer S, Stamm ADB. (2013). Análisis experimental del comportamiento de huellas labiales en cadáveres frescos usando el método Fraile. Gaceta internacional de ciencias forenses, (8), $16-24$

19. Chalapud D, Mosquera, MF, Pulgarín, MF, Cruz C, Moreno F. (2011). Análisis queiloscópico en estudiantes de odontología de la ciudad de Cali.Revista Estomatología, 19(1).

20. Hernández JCM, Pabón YNO, Paredes JFM. Identificación de sexo mediante queiloscopia en Santander, Colombia: una herra- mienta para la medicina forense. Estudio inicial. Revista Española de Medicina Legal. 2015; 41(3):111-116.

21. Quiroz J. Mordeduras Humanas Análisis Pericial y Aplicación Forense. Lima, Perú: Fondo Editorial Universidad de San Martin de Porras. 2014.

22. Muñoz MDCN, Pitarch PG. Valoración del daño corporal por mordeduras: estudio de sentencias de la Audiencia Provincial de Castellón. Gaceta internacional de ciencias forenses. 2012; (4): 4-15.

23. Moses GC. Rugoscopia, Queiloscopia, Oclusografía y Oclusoradiografía como métodos de identificación en odontología forense. una revisión de la literatura. Acta Odontológica Venezolana. 2008.

24. Tornavoi DC, da Silva RHA. Rugoscopia palatina e a aplicabilidade na identificaçáo humana em odontologia legal: revisão de literatura. Saúde, Ética \& Justiça. 2010; 15(1).

25. Toledo V, Ibarra L, Rojas V, Ciocca L, Rocha N, Jara G. Comparación de los patrones de huellas de mordedura según forma del cráneo, mediante el análisis morfológico y morfométrico de semiarcadas dentarias de perro doméstico (Canis familiaris). Avances en Ciencias Veterinarias. 2010; 25(1-2). 